\title{
Analisis Teknik Permainan Bulutangkis Pada Atlit PB Indocafe Medan
}

\author{
Indra Sitorus, David Siahaan \\ Fakultas Ilmu Keolahragaan, Universitas Negeri Medan \\ Indrasitorus072019@gmail.com,davidsiahaan@unimed.ac.id
}

\begin{abstract}
Abstrak: Penelitian ini bertujuan untuk mengetahui kemampuan teknik bermain atlet bulutangkis PB. Indocafe Medan Tahun 2020. Sampel dalam penelitian ini adalah 4 pemain tunggal dan 3 pemain ganda. Metode yang digunakan adalah metode penelitian kualitatif deskriptif. Instrumen penelitian berupa observasi pada hasil pertandingan Daihatsu Astec Open Tahun 2020 di Sumatera Utara. Adapun teknik-teknik yang dianalisis yaitu short servis, long servis, net clear/ lob, dropshoot, drive, smash, overhead lob dan overhead lob. Teknik analisis data yang digunakan adalah dengan rumus persentase. Hasil yang didapatkan dari analisis video yaitu persentase teknik pukulan, dalam permainan tunggal / single yang memiliki tingkat tertinggi pada kemampuan teknik bermain sebesar $89.1 \%$, dengan persentase pukulan point $19.2 \%$ dan kegagalan $10.9 \%$. Sedangkan, dalam permainan ganda / double yang memiliki tingkat tertinggi pada kemampuan teknik bermain sebesar $91 \%$ dengan persentase pukulan point $11,7 \%$ dan kegagalan $9 \%$.
\end{abstract}

Kata Kunci : Analisis, teknik pukulan, Bulutangkis

\section{Analysis of Badminton Game Techniques for PB Indocafe Medan Athletes}

\begin{abstract}
This study aims to determine the technical ability to play PB badminton athletes. Indocafe Medan 2020. The samples in this study were 4 single players and 3 doubles players. The method used is the descriptive qualitative research method. The research instrument was in the form of observations on the results of the 2020 Daihatsu Astec Open in North Sumatra. The techniques analyzed are short serve, long service, net clear/lob, drop shot, drive, smash, overhead lob, and overhead lob. The data analysis technique used is the percentage formula. The results obtained from the video analysis are the percentage of hitting techniques, in a single game that has the highest level of technical playing ability of $89.1 \%$, with a percentage of $19.2 \%$ point strokes and $10.9 \%$ failure. Meanwhile, in the double game which has the highest level of technical ability to play by $91 \%$ with a percentage of $11.7 \%$ and $9 \%$ failure.
\end{abstract}

Keywords: Analysis, the stroke technique, Badminton

\section{PENDAHULUAN}

Permainan bulutangkis adalah cabang olahraga yang banyak digemari oleh masyarakat di seluruh dunia, tidak terkecuali di Indonesia. Hal ini dapat dilihat dengan banyaknya masyarakat yang ikut serta dalam setiap kegiatan olahraga bulutangkis yang diselenggarakan, baik dalam bentuk pertandingan lokal, hingga tingkat dunia, seperti Thomas dan Uber Cup dan Olimpiade atau Sea Games. Menurut M.L Johnson (1984: 5) bulutangkis atau badminton dapat dikatakan sebagai olahraga hiburan dan pertandingan yang digemari oleh usia yang tua dan juga usia yang muda di seluruh dunia. Sedangkan menurut Subardjah (2000:1) permainan bulutangkis merupakan permainan individual yang dapat dimainkan dengan cara bermain tunggal yaitu satu orang melawan satu orang atau bermain ganda yaitu dua orang melawan dua orang dengan menggunakan raket sebagai alat pemukul dan shuttlecock sebagai obyek yang dipukul, lapangan permainan berbentuk persegi empat 
dan dibatasi oleh net untuk memisahkan antara daerah permainan sendiri dan daerah permainan lawan. Bulutangkis merupakan olahraga prestasi yang mampu mengharumkan nama bangsa Indonesia ditingkat dunia. Untuk dapat mencapai prestasi yang terbaik banyak unsur-unsur didalamnya, diantaranya: pengusaan teknik, fisik, taktik dan mental.

Menjadi pebulutangkis yang handal perlu berbagai macam persyaratan, salah satunya adalah penguasaan teknik dasar permainan bulutangkis. Menurut James Poole $(2018 ; 17)$ bahwa keterampilan bulutangkis di bagi dalam empat bagian yaitu pegangan raket (grip), pukulan pertama atau servis (service), pukulan melewati kepala (overhead stroke) dan pukulan ayunan rendah (overhand stroke). Lebih detail mengenai teknik dasar bermain bulutangkis diantaranya adalah teknik service, smash, lob, drop, drive, overhead dan jug footwork. Bulutangkis merupakan olahraga yang menggunakan alat yang dinamakan raket dan shuttlecock, yang dimainkan oleh dua orang atau empat pemain (Arganata, 2016; Maulina, 2018). Cara memainkan olahraga ini adalah dengan memukul shuttlecock dengan menggunakan raket dengan target melewati net yang terletak di tengah lapangan. Jatuh shuttlecock harus tepat berada di daerah lawan, begitupun sebaliknya. Servis menjadi teknik utama dan paling mendasar dalam permainan bulutangkis (Putri, 2013), sehingga teknik dasar ini wajib dikuasai. Pukulan servis (service) merupakan pukulan pertama yang mengawali suatu permainan bulutangkis (Poole, 2011:21). Smash menjadi teknik utama dan paling ampuh untuk mengakhiri sebuah rally panjang untuk mendapatkan poin (Prasojo \& Yahya, 2017; Vernando, Adi, \& Wahyudi, 2017) dan mengakhiri sebuah permainan (Putri, 2013), sehingga teknik tersebut wajib dimiliki dan dikuasai.

Teknik dasar permainan bulutangkis tersebut harus dikuasai pebulutangkis untuk menunjang atau mencapai tujuan permainan. Taktik dan strategi adalah komponen yang sangat penting dalam permainan bulu tangkis. Strategi adalah rancangan atau konsep yang bersifat metodis sebelum permainan atau pertandingan berlangsung. Taktik adalah penerapan atau pelaksanaan dari strategi. Dengan taktik dan strategi yang tepat, seorang pemain dapat memenangkan suatu perrmainan dengan efisien. Taktik dan strategi menunjang pemain untuk bermain secara pandai.

Dari hasil observasi yang telah dilakukan di klub PB. Indocafe Medan saat berlatih di gedung PBSI Sumatera Utara bahwasanya atlet PB Indocafe Medan masih belum bisa menguasai teknikteknik bulutangkis sehingga shuttlecock yang di pukul masih sering terbentur net dan kadang saat memukul shuttlecock terlalu keras sehingga keluar atau (out). Dan pelatih masih belum pernah melakukan teknik evaluasi pertandingan melalui analisis video pertandingan atlet PB Indocafe Medan, seorang pelatih sangat membutuhkan analisis video atlet saat bertanding agar pelatih dapat mengetahui dimana kelemahaan dan kekuatan atlet. Dengan analisis yang tepat maka pelatih dapat memberikan perbaikan atau evaluasi pada kemampuan teknik dan taktik PB Indocafe demi tercapainya penguasaan teknik yang sempurna pada saat bertanding sehingga bisa meminimalisir kesalahan yang dapat mengakibatkan poin bagi lawan. Dari hasil pengamatan tersebut penulis menemukan kemampuan bermain selama pertandingan, pukulan yang gagal, dan pukulan yang menciptakan poin pertandingan dari kedua pemain tersebut. Kemampuan teknik dan taktik yang di miliki kedua pemain tersebut menjadi perhatian untuk diamati dari segi teknik dan taktik, serta faktor faktor lainya saat pertandingan.

Untuk meningkatkan kemampuan setiap pemain bulutangkis perlu kiranya melakukan evaluasi terhadap kemampuan atlet setiap mengikuti pertandingan bahkan juga pada saat latihan. Evaluasi dapat dilakukan mulai dari kemampuan bermainnya seperti kemampuan teknik dan juga taktik bermain. Selain itu dapat juga dievaluasi kondisi fisik yang mendukung kemampuan yang mendukung pelaksanaan teknik dan taktik selama permainan berlangsung serta mental pemain dimana kemampuan kejiwaan atlet untuk menghadapi situsi pertandingan seperti bagaimana sikap pemain jika ketinggalan point, bagaimana sikap pemain jika penonton ribut, sikap pemain jika juri atau wasit tidak memberikan keputusan yang benar. Semua itu penting untuk dianalisis demi kemajuan atau kemampuan atlet dalam bermain bulutangkis untuk menjadi juara.

Analisis pada teknik bermain perlu dilakukan sebagai bahan evaluasi untuk peningkatan kemampuan teknik bermain atlet yang dievaluasi. Selain itu hasil analisis menjadi data yang penting bagi atlet dan pelatih untuk menyusun dan melaksanakan program latihan yang berbasis akan data hasil pertandingan. Sehingga kekurangan-kekurangan dalam kemampuan teknik dapat dilatih lebih fokus dan diperbaiki untuk meningkatkan kemampuan teknik bermain itu sendiri. 
Analisis teknik pada penelitian ini dilakukan pada short servis, long servis, dropshoot, net clear/ lob, smash, drive, overhead lob, overhead drop pada atlet PB Indocafe Medan yang mengikuti kejuaraan Daihatsu Astec Open Tahun 2020. Melakukan analisis pada pertandingan bulutangkis menjadi penting agar dapat meningkatkan kemampuan atlet dengan melakukan evaluasi mendalam. Setiap atlet perlu diberi masukan apa kelebihan dan kekurangnnya sehingga bias menjadi bahan perbaikan selama latihan dilakukan. Pada saat bertanding setiap lawan akan menyerang ke sisi pemain paling lemah sehingga kelemahan tersebut harus diketahui atlet baru dilakukan perbaikan. Perlu dilakukan analisis hasil pertandingan pada atlet PB Indocafe Medan untuk bahan evaluasi agar pertandingan yang dilakukan lebih bermutu dan dapat meningkatkan prestasi. Dari masalah diatas penulis ingin menganalisis pertandingan single dan double antara pemain bulutangkis PB. Indocafe Medan dengan lawan mainnya dari segi keberhasilan dan kegagalan pukulan saat bertanding. Tujuan penelitian ini adalah untuk mengetahui kemampuan teknik bermain atlet bulutangkis PB. Indocafe Medan Tahun 2020.

\section{METODE}

Penelitian ini dilaksanakan di gedung bulutangkis PBSI Medan. Populasi dalam penelitian ini adalah seluruh atlet PB Indocafe Medan yang mengikuti pertandingan Daihatsu Astek Open Tahun 2020. Tehnik pengambilan sampel pada penelitian ini adalah purposive sampling, dengan ketentuan atlet yang mengikuti pertandingan Daihatsu Astek Open Tahun 2020 dan diprediksi pelatih dapat menjadi juara baik pada pertandingan putra maupun putri. Adapun jumlah sampel adalah 4 pemain tunggal dan 3 pasang pemain ganda. Pemain-pemain inilah yang akan dianalisis teknik bermainnya.

Metode penelitian ini adalah kualitatif deskriptif yang bertujuan untuk menganalisis keterampilan teknik dan taktik yang dominan dipakai oleh atlet PB Indocafe Medan dalam pertandingan yang sebenarnya. Iqbal Hasan (2001:7), Statistik deskriptif adalah bagian dari statistika yang mempelajari tentang cara pengumpulan data dan penyajian data sehingga mudah dipahami. Statistika deskriptif hanya berkaitan dengan uraian atau keterangan-keterangan tentang suatu data atau keadaan. Dengan kata lain, statistika deskriptif memiliki fungsi untuk menjelaskan suatu keadaan, gejala, atau persoalan. Penarikan kesimpulan dalam statistik deskriptif hanya ditujukan pada kumpulan data yang ada. Sedangkan menurut Bambang Suryoatmono (2004:18), Pengertian statistika deskriptif adalah statistika yang menggunakan data pada suatu kelompok untuk menjelaskan atau menarik kesimpulan tentang kelompok itu saja

Pengumpulan data yang dilakukan untuk menganalisis hasil pertandingan adalah dengan melakukan observasi selama pertandingan berlangsung (Achmad K. Umam: 2017). Adapun langkah penelitian ini adalah: (1) Merekam pertandingan dengan menggunakan alat perekam video, (2) Melakukan analisis menggunakan aplikasi pemutar video yang dapat diperlambat maupun dipercepat dan (3) Menentukan teknik-teknik yang dianalisis yaitu short servis, long servis, net clear/ lob, dropshoot, drive, smash, overhead lob dan overhead lob. Selanjutnya teknik tersebut akan dihitung persentase keberhasilan dan juga kegagalannya.

\section{HASIL DAN PEMBAHASAN}

Data yang sudah diperoleh akan dianalisis dengan aplikasi pemutar video untuk melakukan permainan dianalisis tahapan gerakan subjek tersebut. Adapun data yang dianalisis dalam hasil penelitian ini yaitu teknik-teknik short servis, long servis, net clear/ lob, dropshoot, drive, smash, overhead lob dan overhead lob. Fokus dalam penelitian ini untuk dianalisis adalah 5 orang pemain tunggal dan 3 pemain double. Dari hasil pertandingan yang diikuti oleh PB Indocafe di turnamen Daihatsu Astec Open 2020 Medan, dengan 4 orang pemain tunggal dan 3 pasang pemain ganda dimana hasilnya hanya 1 orang yang dapat mencapai babak 16 besar pada pertandingan tunggal dan 1 pasangan ganda yang dapat mecapai babak quarter final pada pertandingan double. 
Tabel 1. Hasil Pencapaian Atlet PB Indocafe Pada Kejuaraan Daihatsu Astec Open 2020

\begin{tabular}{lccccccc}
\hline \multicolumn{1}{c}{ Nama } & $\begin{array}{c}\text { Kelompok } \\
\text { Usia }\end{array}$ & $\begin{array}{c}\mathbf{6 4} \\
\text { besar }\end{array}$ & $\begin{array}{c}\mathbf{3 2} \\
\text { besar }\end{array}$ & $\begin{array}{c}\mathbf{1 6} \\
\text { Besar }\end{array}$ & $\begin{array}{c}\text { Quarter } \\
\text { Final }\end{array}$ & $\begin{array}{c}\text { Semi } \\
\text { Final }\end{array}$ & Final \\
\hline \multicolumn{1}{c}{ Single } & & & & & & & \\
\hline Erlangga J.A & TAPA & $\sqrt{n n y y y y y}$ & $\sqrt{ }$ & $\sqrt{ }$ & $\mathrm{X}$ & $\mathrm{X}$ & $\mathrm{X}$ \\
\hline Ramzi A.D & TAPA & $\sqrt{ }$ & $\sqrt{ }$ & $\mathrm{X}$ & $\mathrm{X}$ & $\mathrm{X}$ & $\mathrm{X}$ \\
\hline Maliq Z.A & TRA & $\sqrt{ }$ & $\mathrm{X}$ & $\mathrm{X}$ & $\mathrm{X}$ & $\mathrm{X}$ & $\mathrm{X}$ \\
\hline Syifa R.C & TAPI & & $\sqrt{ }$ & $\mathrm{X}$ & $\mathrm{X}$ & $\mathrm{X}$ & $\mathrm{X}$ \\
\hline \multicolumn{1}{c}{ Double } & & & & & & & \\
\hline Erlangga / Haryono P.Z & GPA & - & $\sqrt{ }$ & $\sqrt{ }$ & $\sqrt{ }$ & $\mathrm{X}$ & $\mathrm{X}$ \\
\hline M. Ilham E. / Zulfan A & GPA & - & $\sqrt{ }$ & $\mathrm{X}$ & $\mathrm{X}$ & $\mathrm{X}$ & $\mathrm{X}$ \\
\hline Ayu W.Z / Nazwa S & GPI & - & $\sqrt{ }$ & $\mathrm{X}$ & $\mathrm{X}$ & $\mathrm{X}$ & $\mathrm{X}$ \\
\hline
\end{tabular}

\section{Permainan Tunggal / Single}

\section{a. Erlangga Japati Asa}

Performance Erlangga Japati Asa pada pertandingan Daihatsu Astec Open 2020 yang di laksanakan di Lapangan PBSI Medan, Sumatera Utara dari round 1,2 dan 3 adalah melakukan total pukulan sebanyak 515 dengan jumlah pukulan yang menghasilkan point 99, relly 360 dan unforced errors sebanyak 56.

Tabel 2. Kesimpulan Performa Permainan Tunggal Erlangga Japati Asa

\begin{tabular}{lccc}
\hline \multicolumn{1}{c}{ Teknik } & \% Point & \% Gagal & Performance \\
\hline Short Servis & $25,0 \%$ & $5,0 \%$ & $95,0 \%$ \\
\hline Long Servis & $9,9 \%$ & $9,9 \%$ & $90,1 \%$ \\
\hline Net Clear/Lob & $12,5 \%$ & $12,5 \%$ & $87,5 \%$ \\
\hline Dropshoot & $17,3 \%$ & $17,3 \%$ & $82,7 \%$ \\
\hline Drive & $9,5 \%$ & $9,5 \%$ & $90,5 \%$ \\
\hline Smash & $11,3 \%$ & $11,3 \%$ & $88,7 \%$ \\
\hline Overhead Lob & $6,3 \%$ & $6,3 \%$ & $93,7 \%$ \\
\hline Overhead Drop & $13,3 \%$ & $13,3 \%$ & $86,7 \%$ \\
\hline \multirow{2}{*}{ Total Pukulan } & \multicolumn{2}{c}{ Stroke on Point } & $19,2 \%$ \\
\cline { 2 - 4 } & \multicolumn{2}{c}{ Unforced Errors } & $10,9 \%$ \\
\cline { 2 - 4 } & \multicolumn{2}{c}{ Performance } & $89,1 \%$ \\
\hline
\end{tabular}

Berdasarkan tabel diatas performance atau kemampuan teknik bermain secara keseluruhan selama pertadingan adalah $89,1 \%$ yang mana pukulan yang dapat menghasilkan point adalah sebesar $19,2 \%$ dan persentase kegagalan dari setiap pukulan adalah 10,9\%. Adapun hasil pertandigan yang dicapai oleh Erlangga Japati Asa pada kejuaraan Daihatsu Astec Open 2020 di Medan adalah sampai pada round 3 atau babak 16 besar.

\section{b. Ramzi Adithya Dalimunthe}

Performance Ramzi Adithya Dalimunthe pada pertandingan Daihatsu Astec Open 2020 yang di laksanakan di Lapangan PBSI Medan, Sumatera Utara dari round 1 dan 2 adalah melakukan total pukulan sebanyak 264 dengan jumlah pukulan yang menghasilkan point 56, relly 164 dan unforced errors sebanyak 44 . 
Tabel 3. Kesimpulan Performa Permainan Tunggal Ramzi Adithya Dalimunthe

\begin{tabular}{lccc}
\hline \multicolumn{1}{c}{ Teknik } & \% Point & \% Gagal & Performance \\
\hline Short Servis & $35,7 \%$ & $0,0 \%$ & $100,0 \%$ \\
\hline Long Servis & $21,4 \%$ & $2,4 \%$ & $97,6 \%$ \\
\hline Net Clear/Lob & $10,0 \%$ & $23,3 \%$ & $76,7 \%$ \\
\hline Dropshoot & $20,0 \%$ & $37,1 \%$ & $62,9 \%$ \\
\hline Drive & $41,2 \%$ & $17,6 \%$ & $82,4 \%$ \\
\hline Smash & $37,5 \%$ & $18,8 \%$ & $81,3 \%$ \\
\hline Overhead Lob & $14,3 \%$ & $11,1 \%$ & $88,9 \%$ \\
\hline Overhead Drop & $41,2 \%$ & $17,6 \%$ & $82,4 \%$ \\
\hline \multirow{2}{*}{ Total Pukulan } & Stroke on Point & & $16,7 \%$ \\
\cline { 2 - 4 } & Unforced Errors & $83,3 \%$ \\
\cline { 2 - 4 } & Performance & & \\
\hline
\end{tabular}

Berdasarkan tabel diatas performance atau kemampuan teknik bermain secara keseluruhan selama pertadingan adalah $83,3 \%$ yang mana pukulan yang dapat menghasilkan point adalah sebesar $21,2 \%$ dan persentase kegagalan dari setiap pukulan adalah $16,7 \%$. Adapun hasil pertandigan yang dicapai oleh Ramzi Adithya Dalimunthe pada kejuaraan Daihatsu Astec Open 2020 di Medan adalah sampai pada round 2 atau babak 32 besar.

\section{c. Maliq Zahran Abhista}

Pada pertandingan Daihatsu Astec Open 2020 yang di laksanakan di Lapangan PBSI Medan, Sumatera Utara pada round 1 yang berhadapan dengan Andika Pradiza dari PB Shamrock, Medan adalah kekalahan 2 set langsung yaitu 14 - 21 dan 12 - 21. Adapun selama pertandingan tersebut Maliq Zahran Abhista melakukan total pukulan sebanyak dengan jumlah pukulan yang menghasilkan point 24 , relly 106 dan unforced errors sebanyak 33.

Tabel 4 Kesimpulan Performa Permainan Tunggal Maliq Zahran Abhista

\begin{tabular}{lclc}
\hline \multicolumn{1}{c}{ Teknik } & \% Point & \% Gagal & Performance \\
\hline Short Servis & $0,0 \%$ & $0,0 \%$ & $0,0 \%$ \\
\hline Long Servis & $12,5 \%$ & $0,0 \%$ & $100,0 \%$ \\
\hline Net Clear/Lob & $0,0 \%$ & $33,3 \%$ & $66,7 \%$ \\
\hline Dropshoot & $20,6 \%$ & $32,4 \%$ & $67.6 \%$ \\
\hline Drive & $10,5 \%$ & $15,8 \%$ & $84,2 \%$ \\
\hline Smash & $20,0 \%$ & $26,7 \%$ & $73,3 \%$ \\
\hline Overhead Lob & $7,7 \%$ & $19,2 \%$ & $80,3 \%$ \\
\hline Overhead Drop & $33,3 \%$ & $0,0 \%$ & $100,0 \%$ \\
\hline \multirow{2}{*}{ Total Pukulan } & Stroke on Point & $14,7 \%$ \\
\cline { 2 - 4 } & Unforced Errors & & $20,2 \%$ \\
\cline { 2 - 4 } & Performance & $79,8 \%$ \\
\hline
\end{tabular}

Berdasarkan tabel diatas performance atau kemampuan teknik bermain secara keseluruhan selama round 1 adalah $79,8 \%$ yang mana pukulan yang dapat menghasilkan point adalah sebesar $14,7 \%$ dan persentase kegagalan dari setiap pukulan adalah $20,2 \%$.

\section{d. Syifa Rossa Chayara}

Hasil pertandingan Syifa Rossa Chayara pada pertandingan Daihatsu Astec Open 2020 yang di laksanakan di Lapangan PBSI Medan, Sumatera Utara pada round 1 yang berhadapan dengan Nayla Shofi Wibowo dari PB Djarum, Kudus adalah kekalahan 2 set langsung yaitu 7 - 21 dan 8 - 21 . Adapun selama pertandingan tersebut Syifa Rossa Chayara melakukan total pukulan sebanyak 112 dengan jumlah pukulan yang menghasilkan point 15 , relly 74 dan unforced errors sebanyak 23 . 
Tabel 5. Kesimpulan Performa Permainan Tunggal Syifa Rossa Chayara

\begin{tabular}{lccc}
\hline \multicolumn{1}{c}{ Teknik } & \% Point & \% Gagal & Performance \\
\hline Short Servis & $25,0 \%$ & $0,0 \%$ & $100,0 \%$ \\
\hline Long Servis & $11,1 \%$ & $11,1 \%$ & $88,9 \%$ \\
\hline Net Clear/Lob & $16,7 \%$ & $16,7 \%$ & $83,3 \%$ \\
\hline Dropshoot & $0,0 \%$ & $60,0 \%$ & $40,0 \%$ \\
\hline Drive & $6,7 \%$ & $13,3 \%$ & $86,7 \%$ \\
\hline Smash & $25,0 \%$ & $8,3 \%$ & $91,7 \%$ \\
\hline Overhead Lob & $8,7 \%$ & $21,7 \%$ & $78,3 \%$ \\
\hline Overhead Drop & $22,7 \%$ & $13,6 \%$ & $86,4 \%$ \\
\hline \multirow{2}{*}{ Total Pukulan } & Stroke on Point & & $13,4 \%$ \\
\cline { 2 - 4 } & Unforced Errors & & $20,5 \%$ \\
\cline { 2 - 4 } & Performance & & $79,5 \%$ \\
\hline
\end{tabular}

Berdasarkan tabel diatas performance atau kemampuan teknik bermain secara keseluruhan selama round 1 adalah 79,5\% yang mana pukulan yang dapat menghasilkan point adalah sebesar $13,4 \%$ dan persentase kegagalan dari setiap pukulan adalah $20,5 \%$.

\section{Permainan Ganda / Double}

a. Pasangan Ganda Erlangga J.A / Haryono P.Z

Hasil pertandingan pasangan Erlangga Japati Asa / Haryo Pambudi Zein pada quarter final yang berhadapan dengan Cardio Doka Putra / William Tanadi dari PB Purnama Solo / PB. Angkasa Prestasi Gemilang, Riau adalah kekalahan 2 set langsung yaitu 12 - 21 dan 15 - 21. Adapun selama pertandingan tersebut pasangan Erlangga Japati Asa / Haryo Pambudi Zein melakukan total pukulan sebanyak 277 dengan jumlah pukulan yang menghasilkan point 24, relly 228 dan unforced errors sebanyak 25.

Berdasarkan tabel diatas performance atau kemampuan teknik bermain Erlangga Japati Asa / Haryo Pambudi Zein secara keseluruhan selama pertandingan adalah $91 \%$ dengan pukulan yang dapat menghasilkan point adalah sebesar 11,7\% dan persentase kegagalan dari setiap pukulan adalah 9\%. Adapun hasil pertandigan yang dicapai oleh pasangan Erlangga Japati Asa / Haryo Pambudi Zein pada kejuaraan Daihatsu Astec Open 2020 di Medan adalah sampai pada quarter final atau babak 16 besar.

Tabel 6. Kesimpulan Performa Permainan Ganda Erlangga J.A/Haryo P.Z

\begin{tabular}{lccc}
\hline \multicolumn{1}{c}{ Teknik } & \% Point & \% Gagal & Performance \\
\hline Short Servis & $7,1 \%$ & $9,4 \%$ & $90,6 \%$ \\
\hline Long Servis & $8,8 \%$ & $17,6 \%$ & $82,4 \%$ \\
\hline Net Clear/Lob & $9,8 \%$ & $8,3 \%$ & $91,7 \%$ \\
\hline Dropshoot & $10,1 \%$ & $16,2 \%$ & $83,8 \%$ \\
\hline Drive & $14,5 \%$ & $8,1 \%$ & $91,9 \%$ \\
\hline Smash & $16,4 \%$ & $6,2 \%$ & $93,8 \%$ \\
\hline Overhead Lob & $12,5 \%$ & $3,1 \%$ & $96,9 \%$ \\
\hline Overhead Drop & $6,0 \%$ & $12,0 \%$ & $88,0 \%$ \\
\hline \multirow{2}{*}{ Total Pukulan } & Stroke on Point & & $11,7 \%$ \\
\cline { 2 - 4 } & Unforced Errors & $9,0 \%$ \\
\cline { 2 - 4 } & Performance & $91,0 \%$ \\
\hline
\end{tabular}

b. Pasangan Ganda M. Ilham. E / Zulfan A

Hasil pertandingan pasangan M. Ilham Efendi / Zulfan Azhariva pada pertandingan Daihatsu Astec Open 2020 yang di laksanakan di Lapangan PBSI Medan, Sumatera Utara pada round 1 yang berhadapan dengan M. Afiq Dzakwan Arief / Moh. Zahki Ubaidillah dari PB Djarum, Kudus / PB 
Djarum, Kudus adalah kekalahan 2 set langsung yaitu 14 - 21 dan 19 - 21. Adapun selama pertandingan tersebut pasangan M. Ilham Efendi / Zulfan Azhariva melakukan total pukulan sebanyak 284 dengan jumlah pukulan yang menghasilkan point 33, relly 221 dan unforced errors sebanyak 30.

Tabel 7. Kesimpulan Performa Permainan Ganda M. Ilham E/Zulfan A

\begin{tabular}{lccc}
\hline \multicolumn{1}{c}{ Teknik } & \% Point & \% Gagal & Performance \\
\hline Short Servis & $0,0 \%$ & $0,0 \%$ & $100,0 \%$ \\
\hline Long Servis & $0,0 \%$ & $9,1 \%$ & $90,9 \%$ \\
\hline Net Clear/Lob & $4,7 \%$ & $9,4 \%$ & $90,6 \%$ \\
\hline Dropshoot & $12,2 \%$ & $9,8 \%$ & $90,2 \%$ \\
\hline Drive & $20,3 \%$ & $16,9 \%$ & $83,1 \%$ \\
\hline Smash & $20,7 \%$ & $15,5 \%$ & $84,5 \%$ \\
\hline Overhead Lob & $5,3 \%$ & $0,0 \%$ & $100,0 \%$ \\
\hline Overhead Drop & $0,0 \%$ & $0,0 \%$ & $100,0 \%$ \\
\hline \multirow{2}{*}{ Total Pukulan } & Stroke on Point & & $11,6 \%$ \\
\cline { 2 - 4 } & Unforced Errors & & $89,6 \%$ \\
\cline { 2 - 4 } & Performance & & \\
\hline
\end{tabular}

Berdasarkan tabel diatas performance atau kemampuan teknik bermain M. Ilham Efendi / Zulfan Azhariva berhadapan dengan M. Afiq Dzakwan Arief / Moh. Zahki Ubaidillah dari PB Djarum, Kudus / PB Djarum, Kudus secara keseluruhan selama round 1 adalah 89,4\% yang mana pukulan yang dapat menghasilkan point adalah sebesar 11,6\% dan persentase kegagalan dari setiap pukulan adalah $10,6 \%$.

\section{c. Pasangan Ganda Ayu W.Z / Nazwa S}

Hasil pertandingan pasangan Ayu Wulandari Zein / Nazwa Salsabilla pada pertandingan Daihatsu Astec Open 2020 yang di laksanakan di Lapangan PBSI Medan, Sumatera Utara pada round 1 yang berhadapan dengan Michelle Zheng / Ni Kadek D. A. Pratiwi dari PB Dwi Jaya, Jakbar / PB Dwi Jaya, Jakbar adalah kekalahan 2 set langsung yaitu 4 - 21 dan 11 - 21. Adapun selama pertandingan tersebut pasangan Ayu Wulandari Zein / Nazwa Salsabilla melakukan total pukulan sebanyak 186 dengan jumlah pukulan yang menghasilkan point 14, relly 147 dan unforced errors sebanyak 25.

Berdasarkan tabel diatas performance atau kemampuan teknik bermain Ayu Wulandari Zein / Nazwa Salsabilla berhadapan dengan Michelle Zheng / Ni Kadek D. A. Pratiwi dari PB Dwi Jaya, Jakbar / PB Dwi Jaya, Jakbarsecara keseluruhan selama round 1 adalah86,6\% yang mana pukulan yang dapat menghasilkan point adalah sebesar $7,5 \%$ dan persentase kegagalan dari setiap pukulan adalah $13,4 \%$.

Tabel 8. Kesimpulan Performa Permainan Ganda Ayu W.Z/Nazwa S

\begin{tabular}{lccc}
\multicolumn{1}{c}{ Teknik } & \% Point & \% Gagal & Performance \\
\hline Short Servis & $0,0 \%$ & $18,8 \%$ & $81,3 \%$ \\
\hline Long Servis & $0,0 \%$ & $0,0 \%$ & $0,0 \%$ \\
\hline Net Clear/Lob & $3,8 \%$ & $18,9 \%$ & $81,1 \%$ \\
\hline Dropshoot & $20,0 \%$ & $10,0 \%$ & $90,0 \%$ \\
\hline Drive & $4,8 \%$ & $4,8 \%$ & $95,2 \%$ \\
\hline Smash & $10,7 \%$ & $21,4 \%$ & $78,6 \%$ \\
\hline Overhead Lob & $8,7 \%$ & $4,3 \%$ & $95,7 \%$ \\
\hline Overhead Drop & $8,0 \%$ & $8,0 \%$ & $92,0 \%$ \\
\hline \multirow{3}{*}{ Total Pukulan } & Stroke on Point & $7,5 \%$ \\
\cline { 2 - 4 } & Unforced Errors & $13,4 \%$ \\
\cline { 2 - 3 } & Performance & $86,6 \%$ \\
\hline
\end{tabular}




\section{SIMPULAN}

Dari hasil analisis teknik atlit PB Indocafe yang telah dilakukan pada saat mengikuti pertandingan bulutangkis Daihatsu Astec Open 2020 di Sumatera Utara maka ditarik kesimpulan sebagai berikut :

1. Erlangga Japati Asa memiliki kemampuan teknik bermain sebesar $89,1 \%$, dengan persentase pukulan menghasilkan point sebesar 19,2\% dan persentase kegagalan setiap pukulan adalah 10,9\%. Kemampuan tersebut hanya dapat membawa Erlangga Japati Asa hingga round 3 atau babak 16 besar.

2. Ramzi Adithya Dalimunthe memiliki kemampuan teknik bermain sebesar $83,3 \%$ dengan persentase pukulan menghasilkan point sebesar $21,2 \%$ dan persentase kegagalan setiap pukulan adalah $16,7 \%$. Kemampuan tersebut hanya dapat membawa Ramzi Adithya Dalimunthe hingga round 2 atau babak 32 besar.

3. Maliq Zahran Abhista memiliki kemampuan teknik bermain sebesar $79,8 \%$ dengan persentase pukulan menghasilkan point sebesar $14,7 \%$ dan persentase kegagalan setiap pukulan adalah 20,2\%. Kemampuan tersebut membuat Maliq Zahran Abhista kalah pada round 1 atau babak 64.

4. Syifa Rossa Chayara memiliki kemampuan teknik bermain sebesar $79,5 \%$ dengan persentase pukulan menghasilkan point sebesar 13,4\% dan persentase kegagalan setiap pukulan adalah 20,5\%. Kemampuan tersebut membuat Syifa Rossa Chayara kalah pada round 1 atau babak 32.

5. Pasangan ganda Erlangga Japati Asa / Haryo Pambudi Zein memiliki kemampuan teknik bermain sebesar $91 \%$ dengan persentase pukulan menghasilkan point adalah sebesar $11,7 \%$ dan persentase kegagalan dari setiap pukulan adalah 9\%. Kemampuan tersebut hanya dapat membuat mereka bermain hingga quarter final atau babak 8 besar.

6. Pasangan ganda M. Ilham Efendi / Zulfan Azhariva memiliki kemampuan teknik bermain sebesar $89,4 \%$ dengan persentase pukulan menghasilkan point sebesar $11,6 \%$ dan persentase kegagalan dari setiap pukulan adalah $10,6 \%$. Kemampuan tersebut membuat membuat mereka kalah pada round 1 atau babak 32 besar.

7. Pasangan ganda Ayu Wulandari Zein / Nazwa Salsabilla memiliki kemampuan teknik bermain sebesar $86,6 \%$ dengan persentase pukulan menghasilkan point sebesar 7,5\% dan persentase kegagalan dari setiap pukulan adalah 13,4\%. Kemampuan tersebut membuat membuat mereka kalah pada round 1 atau babak 32 besar.

Dari hasil penelitian tersebut masih sangat disarankan kepada pemain atlit PB Indocafe yang mengikuti pertandingan bulutangkis Daihatsu Astec Open 2020 di Sumatera Utara untuk melakukan latihan lebih giat memperbaiki teknik bermainnya dimana masih banyak kekurangan pada Teknik Teknik seperti short servis, long servis, net clear/ lob, dropshoot, drive, smash, overhead lob dan overhead lob. Kemampuan setiap pemain bulutangkis untuk menguasai Teknik tersebut menjadi sebuah keharusan agar dapat memenangkan setiap pertandingan dimana kekurangan salah satu Teknik saja menjadi kelemahan yang akan dimanfaatkan oleh lawan untuk menghasilkan point. Juga kepada pelatih agar memberikan drill atau latihan khusus untuk memperbaiki Teknik yang sering salah atau melakukan unforced error sehingga kesalahan kesalahan yang tidak perlu dilakukan tidak terulang kembali di pertandingan berikutnya.

\section{DAFTAR PUSTAKA}

Achmad Khoirul Umam. 2017. Analisis keterampilan teknik bermain pada permainan tunggal dan ganda putra dalam cabang olahraga bulutangkis. Jurnal Kesehatan Olahraga Vol. 05.No. 03 Tahun 2017, hal 1-8.

Arganata, M. A. (2016). Kekalahan Pemain Bulutangkis Ganda Putra Indonesia Dari Pemain Ganda Putra Korea. Jurnal Kesehatan Olahraga

Hasan, Iqbal (2004), Analisis Data Penelitian Dengan Statistik, Jakarta: PT. Bumi Aksara 
Husaini Usman. (1998). Metodologi Penelitian Sosial. Jakarta: Bumi Aksara.

James Poole, (2018) Belajar Bulutangkis, Bandung, Pionir Jaya.

M. L. Johnson. (1984). Badminton: Bimbingan Bermain Bulutangkis. alih bahasa, IS. Daulay. Jakarta: PT Mutiara Sumber

Prasojo, D. A., \& Yahya, A. (2017). Pengaruh Umpan Tetap Dan Umpan Berubah Terhadap Akurasi Smash Dalam Permainan Bulutangkis Smk Penerbangan Singosari 2016/2017. JP.JOK (Jurnal Pendidikan Jasmani, Olahraga Dan Kesehatan). https://doi.org/10.33503/jpjok.v1i1.2 48

Putri, H. N. (2013). Analisis Pertandingan Bulutangkis Final Tunggal Putra Pada Olimpiade Musim Panas XXX di London 2012. E-Journal Unesa.

Subardjah. (2000). Bulutangkis. Departemen Pendidikan Nasional

Suryoatmono, Bambang. (2004). Statistika Non Parametrik dan Penerapannya dalam Penelitian Manajemen. Bandung 